\title{
Eradicating Poverty among Women in Rural Agriculture: Imperative for National Development DOI: 10.36108/NJSA/4102/12(0230)
}

\author{
Anthony Abayomi Adebayo \\ Department of Sociology \\ Federal University \\ Oye-Ekiti. Ekiti State, Nigeria \\ adebayo_nthny@yahoo.com
}

\begin{abstract}
The agricultural sector in Nigeria is an area where gender inequity, leading to women subjugation and exploitation, is very evident. In spite of the enormity of the roles played by women in various agricultural production activities, the sector is still largely regarded as a man's world. Statistics, however, have shown that rural women, more than their male counterparts, are involved in agriculture, constituting up to 60-80 percent of the labour force. It is therefore, ironical that their contributions to agriculture and rural development are seldom noticed or rewarded. This paper investigated the relationship between gender inequality in agriculture and impoverishment of rural women and its implication for national development. Beyond identifying the causes of gender inequity, it made context-specific recommendations towards its eradication.
\end{abstract}

Keywords: impoverization, rural women, agriculture, decision making, national development

Investing in girls and women is likely to prevent intergenerational cycles of poverty and yield high economic and societal returns.

\section{Ban Ki-Moon, United Nations Secretary-General}

It is impossible to realize our goals while discriminating against half of the human race.

\section{Kofi Annan, Former United Nations}

\section{Introduction}

Over the ages and in many societies, inequity between women and men has been part and parcel of a seemingly accepted male-dominated culture. According to Olujimi (2009), the prejudice against women has been an agelong situation. It is a complex historical process, which requires detailed study before one can conceive of a viable strategy to improve and sustain the status of women in society (Prakash, 2003). In Nigeria, women are often marginalized in the access to economic, political and social resources compared to men, rendering them relatively poorer than their male counterparts (Ajani, 2008). Gender discrimination has created wide gender gap in many 
countries of the world, with serious social, economic and health consequences on female members.

From the workplace to the home, women continue to suffer all forms of degradation and deprivation. Women were seen by male factory workers as a threat to their employment; with the employment of women as wage earners, men were quick to perceive them as a rival group and made use of economic, legal and ideological weapons to eliminate or reduce their competition (Hacker, 1972; Adebayo, 2013a). This discrimination and deliberate attempts at impoverishing women are evident in rural areas in Nigeria, where the role of women continues to remain subservient to the men.

The bulk of the poor, some three-quarters, according to a recent World Bank estimate, live in the rural areas where they draw their livelihood from agriculture and related activities (Kotze, 2003). Indeed, development, food security and poverty alleviation will not be truly achieved without rapid agricultural growth. Assisting the rural poor to enhance their livelihoods and food security in a sustainable manner is therefore a great challenge. Broadly speaking, increases in agricultural productivity are central to growth, income distribution, improved food security and alleviation of poverty in rural Africa. In all of these, the rural woman plays a pivotal role and crucial to the overall success of efforts directed at agricultural development in rural areas (FAO, 2002; Ogunlela \& Mukhtar, 2009).

The various interventions towards women emancipation by the different regimes in Nigeria have yielded little or no results. These include the establishment of the Federal Ministry of Women Affairs in 1995, the Better Life for Rural Women programme, the Family Support Programme (FSP), and the Family Economic Advancement Programme (FEAP) all of which were aimed at strengthening women's role in development. However, this approach to women development has been faulted for its inability to inculcate and achieve the actual development needs of women. Instead of achieving gender equity, most development programmes using this approach have further deepened the crisis and in some instances, tended to increase women subordination (Abdullahi, Adekeye \& Shehu, 2011).

In the same vein, Ajah (2010) observed that one of the reasons that necessitated the establishment of Women-in-Agriculture (WIA) Programme in 1989 was the view that women farmers were not having adequate access to extension services compared to their male counterparts. Over the last couple of decades, considerable efforts have been made globally to provide women farmers with efficient, effective and appropriate technology, training and formation. In Nigeria, part of the efforts made in improving the status of women farmers resulted in the institutionalization of a gender sensitization and communication intervention programme known as Women-in-Agriculture in 1989. It was institutionalized by the Federal Government of Nigeria because of the need to improve extension services to women farmers and to improve their yield (output) and income (Ajah, 2010). Sadly, the effect of the programme is largely yet to be seen. 


\section{Women in Agriculture in Nigeria}

For a long time, there seemed to have been concerted efforts to subdue and impoverish women in almost all facets of life. The public discrimination against women is a manifestation of the desire for dominance (Mill, 2006). African women are known to contribute to development in the various sectors of the society, yet the subordination of women to men remains striking across generations and ethnic groups. It touches marriage, employment and even in education (Osuji, 2004 ; Alade, 2013). This is done in order to ensure that the womenfolk remain subjected to the whims and caprices of men. According to Gusim (2012), women contribute tremendously to agricultural output but unfortunately they hardly benefit from agricultural incentives and innovation because of economic suppression, social and traditional practices which undermine the constitutional provisions on the equality of men and women.

Furthermore, as Ajani (2008) revealed, women contribute significantly to food production, processing and marketing, while men control farm decisions and productive resources. All over the world, agricultural activities such as planting, weeding, harvesting and marketting among others have always involved both men and women. While men play their own part, women also play significant part in various agricultural production activities in the areas of food crop farming, food processing and marketing. For Chiebowska (1990), women living in rural areas represented 60 percent of the world's female population, with as much as 70 percent of them in the developing countries, consisting two-fifths of the active population in agriculture. The activities of women in agroforestry and soil conservation not only provide major support for food production, but also promote the sustainability of ecosystems (Ajani, 2008). It is further argued that in many countries, the diminishing capacity of agriculture to provide for household subsistence increased the workload shouldered by women as men withdrew their labour from agriculture (IFAD, 1993). In recent decades, the number of men migrating from rural areas in search of employment has increased ; the number of households headed solely by women has grown substantially (IFAD, 2009). The scenario whereby more and more men either temporarily or permanently migrate has caused shortage of labour in the rural areas. As a result, more women are left behind to do much of the farm work as paid or unpaid family labour (Abdullahi, 2006).

Women play an indispensable role in farming and in improving the quality of life in rural areas. However, their contributions often remain concealed due to some social barriers and gender bias. Culture and sub-cultures in Nigeria give preference to the masculine gender as they are usually regarded as the heir or even pillars of the family (Alade, 2013). Even government programmes often fail to focus on women in agriculture. Despite the contributions of women in the agricultural sector as well as in other developmental processes, their roles in promoting economic and social change continues to be inadequately recognised and undervalued (Oluwasola, 1998). This undermines 
the potential benefits from programmes, especially those related to food production, household income improvements, nutrition, literacy, poverty alleviation and population control. Equitable access for rural women to educational facilities would certainly improve their performance and liberate them from their marginalised status in the society. Other areas where women's potential could be effectively harnessed are agricultural extension, farming systems development, land reform and rural welfare.

In Nigeria, women constitute about 49.7 percent of the total population (CBN, 1994) and findings from a study financed by the United Nations Development Programme (UNDP) revealed that women make up some 60-80 percent of agricultural labour force in Nigeria World Bank, 2006). Furthermore, women are known to be more involved in agricultural activities than men in sub-Saharan Africa, including Nigeria. As much as $73 \%$ were involved in cash crops, arable and vegetable gardening, while post-harvest activities had 16\% and agroforestry, 15\% (Abdullahi, 2006). The issues of gender bias and equity point to the double burden women have to bear - that on being poor and being women. Furthermore, strategies and programmes for development had largely overlooked the question of gender equity. Projects aiming to reduce poverty view the poor rural women as the recipient of benefits of development, instead of active participants; yet these women have the least access to basic needs such as food, health and education (Prakash, 2003).

\section{Theoretical Framework}

The Social Learning Theory is a popular explanatory perspective in gender relations (Oladeji, 2009). The theory, as propounded by Albert Bandura (1977), is the guiding framework for this study. Social learning theory is a perspective that states that people learn within a social context. It emphasizes concepts such as modeling and observational learning. People, especially children, learn from the environment and seek acceptance from society by learning through role models. Social learning theory posits that social behaviour (any type of behaviour that we display socially) is learned primarily by observing and imitating the actions of others.

Gender differentiation, statuses and roles are part of the social system. As children grow up, they are socialized into the societal definition of the gender statuses and roles in their environment. This definition is seen as the norm and is therefore perpetuated by successive generations. A society that is patriarchal in nature transmits such ways of life into the children, who in turn grow up and socialized their own children the same way. For instance, the child of a farmer who grew up to know his mother as an appendage of his father, who has little or no contribution to the farming decision making, and worse still, has no inheritance rights to her own father's property because she is female, is bound to perceive such way of life as the norm and culture. He shall also socialize his own children in like manner. Therefore, even though the role that women play and their position in meeting the challenges of agricultural production and 
development is quite dominant (Nnadozie \& Ibe, 1996; Rahman, 2008; Ogunlela \& Mukhtar, 2009), they remained unsung heroes as the society only expected them to work for the men, due to the preconceived notions and stereotypes about the gender statuses and roles.

According to Bandura (1977), observational learning can occur in relation to three models:

- Live model - this is the process in which an actual person is demonstrating the desired behaviour.

- Verbal instruction - in which an individual describes the desired behaviour in detail, and instructs the participant on how to engage in the behaviour.

- Symbolic - in which modeling occurs by means of the media, including movies, television, internet, literature, and radio. This type of modeling involves a real or fictional character demonstrating the behaviour.

\section{Overview of Gender Inequality in Rural Areas in Nigeria}

Women in general, face different challenges and opportunities in many areas than similarly situated men do (Danziger, 2009). The situation is worse for the rural women who have low literacy level and consequently have become mere tools in the hands of their husbands (Shittu, 2009). Rural women work tirelessly as they are either engaged on the farms or in petty trading to make ends meet for their families. Some after a tiring day of labour return to abusive husbands. According to Ifemeje and Ikpeze (2012), Nigeria, after several decades of ratification of CEDAW, has failed to domesticate the international instrument as part of her municipal laws. This regrettably has seriously slowed down the pace of women emancipation in the country.

Consequently, women who constitute half the total Nigerian population, still continue to suffer intense marginalization and relegation to the background. They are discriminated against in virtually all spheres of life in Nigeria, for instance, in the home front, in educational institutions, in working place and in political appointments. The worrisome aspect of this discrimination is that it has persisted for so long that it is now so deeply rooted and institutionalized that eradicating it poses an uphill task. Women lag behind men in most indicators of socio-economic development. Women constitute the majority of the poor, the unemployed and the socially disadvantaged, and they are the hardest hit by the current economic recession, with about 50 percent of the rural women living below poverty line (Ajani, 2008).

Over 70 percent of Nigerians live in the rural areas where traditional values are held tenaciously. In such traditional societies, women are regarded as "properties" of their husbands and the power to make decisions lies with the men (Oluwasola, 1998). Women are often projected as those who lack initiative and needed to be guided and monitored in whatever they do (Olujimi, 2009; Adebayo, 2013). In spite of women's enormous contribution to food production, their access to needed farm resources has been very low, due to 
marital and religious factors. Other reasons include low literacy rate, lack of ownership and control of assets, lack of sufficient and substantive collateral and inadequate knowledge and training in use of improved technologies (Ajani, 2008). These factors negatively affect the productivity of women and ensure that they remain subservient.

Several factors have been advanced for these intense discriminations and marginalization. The factors include Nigerian patriarchy which is embedded in the cultural system. The Nigerian culture perceives and treats men as superior to women and this is well manifested in the "son preference syndrome" that is prevalent in Nigeria. During the period of socialization, males are usually believed to be superior to females and thus, are exposed to different roles (Alade, 2013). The culture equally disinherits wives and daughters. In the home front, women are subjected to all sorts of inhuman and degrading treatment. The culture strictly restricts women to the stereotyped role of home keeping, child bearing and childrearing. She is to be seen and not heard (Ifemeje and Ikpeze, 2012). The subordination of women knows no boundaries or barriers, and is not dependent on the social, educational, religious or economic status of the Nigerian women.

The low level status accorded women in the traditional African society has denied women access to basic social and economic opportunities capable of enhancing their productivity. The low level of female education and their limited access to skill acquisition compounded by a culture of early marriage, particularly in the rural areas, enable young married women to enter the rural agricultural economy without any natural advantage over their forebears. This has resulted largely in the perpetuation of poverty among rural women more than any other group in the country.

\section{Causes of Impoverization of Women in Agriculture Culture and Tradition}

Customary practices across Nigeria generally hold that the man is the head of the house and has the absolute control in the decision making process of the home. That is, a patriarchal society reinforces the norm that views men as leaders and women as followers (Adebayo, 2013). Evidently there are serious constraints which militate against the promotion of an effective role for women in development in those societies which were bound by age-old traditions and beliefs, which for Momodu (2002) is that rural women in Nigeria have developed a culture of silence, resignation and docility. Patriarchal modes and practices motivated by cultures and/or interpretations of religious sanctions and illiteracy hinder women's freedom to opt for various choices to assert greater mobility in social interactions. Resulting from these situations, women's contribution to agriculture and other sectors in the economy remain concealed and unaccounted for in monitoring economic performance measurement. Consequently, they are generally invisible in plans and programmes (Prakash, 2003). 


\section{Denial of Access to Land}

Most customary laws in Nigeria are patriarchal in nature and therefore do not recognize daughter/wife inheritance of father/husband's landed property, especially in South-eastern Nigeria. Land devolves only on the male lineage thereby disempowering women economically. The patriarchal nature of most rural societies does not provide women with the same rights to land as it does men. Social institutions and practices are in some cases reinforced by formal legislation. In most sub-Saharan African countries only men have the right to land ownership. If a woman inherits land from her father, her husband takes control of it. If the woman is unmarried, control passes to a male in her family. When a woman's husband dies, title passes to her son. Under these circumstances women may only have the right to lifetime tenancy. To take the example of a husband who grants his wife the temporary right to a piece of land to grow crops to feed the family, the outcome for her may be very negative. She cannot borrow because she cannot pledge the land as collateral. She may only use the land for the purpose of feeding her family. She cannot grow cash crops which would bring in an income for her own use (Jutting and Morrisson, 2009). In spite of the provisions of the constitution of the Federal Republic of Nigeria, gender discrimination in land and property rights continues to exist (Itua, 2012).

This has been the lot of women in Nigeria, especially in the South-east, until the Nigerian Court of Appeal in the case of Mojekwu. v. Ejikeme struck down this discriminatory system of inheritance, which disinherited the daughters of a deceased man from inheriting their father's landed property in preference of their uncle. . . The Nigerian Court of Appeal also held that such a custom was contrary to public policy and repugnant to natural justice equity and good conscience (Ifemeje and Ikpeze, 2012). However, despite this landmark court decision and pronouncement, the situation has not changed. Women are still being excluded from land inheritance in many parts of Nigeria, and in cases where the women inherit some land, it is passed over to the husband. They are, in fact, discriminated against by stereotypes which restrict them to a reproductive role, and denied access to resources which could eventually enhance their social and economic contribution to the society.

\section{Division of Labour between the sexes}

One of the basic factors causing unequal share of women in development relates to the division of labour between the sexes. Social institutions and practices with stable rules of behaviour that are outside the formal system, determine to a large extent the types of jobs that are available to women and the particular working conditions associated with them. Most production was for household consumption and men basically controlled the marketing process. When cash crops were grown, men generally took most of the income from sales while the role of women was that of contributing family workers 
(Jutting and Morrisson, 2009). An example is a household where the husband looks after the production of cash crops, which brings in an income, the wife takes care of crops grown for family consumption. In this way, the wife depends on the husband's reallocation of money within the household. Another example is the case where the wife may help her craftsman husband but she is not paid for her work.

The Nigerian society is basically patriarchal and women's place within the scheme is decidedly subordinate (Adebayo, 2013b). Hence, division of labour has tended to relegate women to roles that present them as subservient to the men, which empowers the men more and makes the women merely supportive. This has been justified on the basis of the childbearing function of women. Consequently, distribution of tasks and responsibilities between men and women in a given society has mainly restricted women to the domestic sphere. This has aggravated poverty and general backwardness for rural women as they have to depend on their husbands for survival. Prakash (2003) contends that while the women's childbearing and child-rearing functions are respected in many countries, there has been very little recognition of women's actual or potential contribution to the economic, social and cultural states. The role of women within the family combined with high level of unemployment and under-employment of the population in general, has led to the unequal state of priority to men in matters of employment. It is understandable that women cannot be expected to join the army, for instance, as foot soldiers but Israel's well-known and rightfully feared sabrahs or women commandos have shattered the myth of man's physical superiority and thus priority for most jobs.

\section{Lack of Access to Vital Information}

Women living in rural areas of Nigeria are generally known to be suffering from general deprivation including access to information resources. Rural women most often fail to access various information resources and services even when such information is available. The reasons may not be unrelated to the socio-economic status of the rural women or the format in which such information is packaged (Onwubiko, 2012). The absence of an effective information system pattern for mobilizing and stimulating women into action with a view to improving their quality of life has continued to be a major issue in the alleviation of women poverty. Many of the training and empowerment programmes have continued to elude women. Appropriate information empowers people towards actions that can transform lives and allow for a greater sense of independence. Rural women need information of all types to improve the quality of their life and their environment. Education and training are essential components of any strategy to improve agricultural and non-farm productivity and pull households out of poverty. Learning about improved production technologies and methods, new products and markets, business and life skills can make a big difference (ILO, 2008), but women have been largely isolated from such vital learning. 


\section{Lack of Access to Credit Facilities}

Most of the time, government and private financial institutions often deny women access to credit that could help improve their endeavours. Since women do not own land, they lack a basic resource that they can use as collateral security to obtain loans. In fact, for a woman to obtain loans at all from the Nigerian Agricultural and Co-operative Bank (NACB), a bank set up to promote agriculture, her husband will have to guarantee her (Oluwasola, 1998). This means that if the husband refuses, access to the credit is blocked. According to Ayu (2009) as cited in Gusim (2012), the 1987 research work of Nema Ngur shows that in a study of 40 women and men in Pella village in Gombia Local Government Area of the former Gongola State, in spite of the high level of awareness of the benefits of adopting agricultural innovations, only men benefited from government loans and were members of cooperatives, et cetera. In the same study (Ayu, 2009) it was discovered that none of the women had benefited from government loans because their husbands would either not approve or when they do, would take the money from them (Gusim, 2012). This has greatly reduced the scale of operation of women in agriculture and further aggravates their level of poverty.

\section{Lack of Access to Agricultural Inputs}

An investigation carried out by Ayu in 1992 amongst the Berom women of Plateau State, shows that all of the 600 women interviewed were aware and desired the benefits of agricultural inputs such as fertilizers, pesticides and tractors but none of them had direct access to it. They had to get such inputs through their husbands who do not get enough of such and must satisfy the needs of their own farms first (Gusim, 2012) because whenever attempts are made to grant farm inputs to women, they are channeled through men (FAO, 1979).

\section{Non-Involvement in Decision Making Processes}

The concern for increasing the quality of life of the rural women in Nigeria can be seen in the general concern to alleviate the socio-economic status of the rural poor household. Many programmes sponsored by either the national government or international agencies have been designed to improve quality of life of the rural women in Nigeria. Worthy to mention is the introduction of the Better life for Rural Women (BLW) in 1987 under late Mariam Babangida, (the then Nigerian first lady) and the Family Economic Advancement Programme (FEAP) under Mariam Abacha (the Nigerian first lady in 1993-97) which were planned to play critical role in alleviating the status of rural women in Nigeria, socially and economically. In recognition of the failure of the past government efforts, some non-governmental organizations stepped up efforts also to improve the quality of life among the women folks living in the rural 
areas. An example is the Country Women Association of Nigeria (COWAN) which started in Ondo State Nigeria in 1982 (Modupe, 2008).

However, most of these programmes have failed to ameliorate the working and living conditions of rural women because women in rural areas for which such programmes were meant were not always involved in the planning and decision making processes which ultimately leads to the failure of such programmes. For instance, findings from a study financed by the United Nations Development Programme (UNDP) revealed that women make up some 60-80 per cent of agricultural labour force in Nigeria, but despite this huge representation, widespread assumption that men - and not women - make key management farm decisions has prevailed. Sadly, female farmers in the country are voiceless, especially in influencing agricultural policies (Ogunlela and Mukhtar, 2009).

\section{Lack of Adequate Education and Training}

Education equips one for a decent living. A truly educated woman or person is one who is able to take positive decisions that concern her without too much strain. However, the average rural woman in Nigeria is exposed to limited education and acquires only few skills which are traditional and tailored towards serving the husband. Also girls are given out in marriage early before developing their full potential. Women often have different training needs than men, linked to other domestic work and care responsibilities, as well as genderbased divisions of labour for managing or undertaking specific tasks in crop, livestock, forestry or fish production and processing. However, women are often denied the opportunity of training to acquire the much needed skills for emancipation and economic development. In the light of this, Quisumbing (1996) argues that when women receive the same levels of education, experience and farm inputs as men, there are no significant differences in male and female farmers' productivity.

However, most times, training programmes are often hijacked by men, depriving women of the opportunity to acquire knowledge for their development. Also, Oluwasola (1998) contends that in a country where agricultural extension services are largely dominated by men, women are bypassed by modern ideas and technological improvements that could raise their productivity, increasing their income generating capacity and improve their general welfare. For developing countries, women are less likely to receive vocational training compared with men. In addition, even in cases where women were as likely as men to receive training, there were significant differences in terms of the amount of training they received. Skills development is particularly important to rural women who are more likely to be contributing family workers, subsistence farmers or home-based microentrepreneurs in the informal sector, or performing low paid, unskilled work as seasonal workers (FAO, 2009). Furthermore, women are less likely than men to be reached by agricultural extension workers, who are supposed to educate and train them to achieve better output. For instance, from the last available 
official survey in 1988, only 7 per cent of agricultural extension services in Africa were directed to women farmers and only about 11 percent of all extension personnel were women (IFPRI, 2009; FAO, 2010).

Impoverization of Rural Women and Implications for Development in Nigeria

Poverty cannot be defined simply in terms of lacking access to sufficient food. It is also closely associated with a person's lack of access to productive assets, services and markets. Without access to these, it is unlikely that production and income earning capacities can be improved on a sustainable basis (ILO, 2008). Rural women who are obliged to attend to all the household chores, children's welfare, nutrition and family cohesion along with farm work, are desperately driven to adopt a survival strategy to save the family food security from total collapse. Consequently, the continued impoverization of the rural women is a danger to food security and sustainable development; but the empowerment of rural women will ultimately lead to significant gains in agricultural productivity.

After some decades of neglect, global problems and issues concerning environment, women in development and poverty have reappeared. All these have emerged in rural communities and threatening their sustainability. Rural communities with norms developed for managing resources are important for the stability of community life. Gender-oriented rural development programmes which focus on role of women to guarantee the stability of life provide a sound basis for integrated development of the quality of life. Moreover, women population in the world halves that of men and if they are empowered and their roles are recognized, articulated and exposed to equal opportunities, development will be rapid as all people are involved productively. Therefore, there is the need to strengthen the participation of women in order to achieve sustainable development (Dada, 2011).

Women rarely have access to the resources that would make their work more productive and ease their heavy workload. Ultimately, it is not just women who are held back, but also their families, their communities and local economies. However, when women are economically and socially empowered, they become a potent force for change. In rural areas of the developing world, women play a key role in running households and make major contributions to agricultural production. But the inequalities that exist between women and men make it difficult for women to fulfil their potential. Women who are supposed to facilitate growth and development are held back by lack of education, unequal property rights and limited control over resources (IFAD, 2011). Consequently, for accelerated growth and prosperity of poor communities, women's needs and rights must be addressed.

Socio-economic goals of productivity, equity and environment stability are closely woven around the agriculture sector policies and new dimensions in 
programmes implemented are already emerging as new values. Regardless of the level of development achieved by the respective economies, women play a pivotal role in agriculture and in rural development in most countries. Gender inequality and limited access to credit, healthcare and education have posed a number of challenges for rural women. This is why one of the deepest roots of poverty is gender discrimination, which imposes a disproportionate burden on women. When women are poor, their rights are not protected. They face obstacles that may be extraordinarily difficult to overcome. This results in deprivation in their own lives and losses for the broader society and economy, as women's productivity is well known as one of the greatest generators of economic dynamism. While both men and women suffer in poverty, gender discrimination means that women have far fewer resources to cope. They are likely to be the last to eat, the ones least likely to access healthcare, and routinely trapped in time-consuming, unpaid domestic tasks. They have more limited options to work or build businesses. Adequate education may lie out of reach. Some end up forced into sexual exploitation as part of a basic struggle to survive (women and poverty/unwomen.org).

Meanwhile, the global food and economic crisis, and climate change have only aggravated the situation. Some 925 million people go hungry every day. But investing in women can generate significant improvements in productivity and food security. Entire communities benefit socially and economically when women have access to land, water, education, training, financial services and strong organizations (women and poverty/ unwomen.org). The empowerment of women and equal opportunities for both sexes are fundamental in reducing poverty, hunger and malnutrition. Furthermore, giving women the same access as men to agricultural resources and inputs could increase production on women's farms 20-30 percent, reducing the number of hungry people in the world by 100-150 million (IFAD, 2011). According to UN Secretary-General Ban Ki-moon in his message for the International Day of Rural Women, "Empowering rural women is crucial for ending hunger and poverty. By denying women rights and opportunities, we deny their children and societies a better future. This is why the United Nations recently launched a programme to empower rural women and enhance food security" (women and poverty/unwomen.org).

The importance of the role of women in agriculture in rural areas in Nigeria cannot be overemphasized. Women, by their numerical strength and activities, play undeniable strategic roles and if they are empowered, there will be accelerated growth and development in the Nigerian polity. However, a further repression and impoverization of the rural women will only lead to a further stagnation of the rural areas and impact negatively on national development. It is, therefore, imperative that old stereotypes that seek to perpetuate restrictions on women must be jettisoned. Bandura (1977) in his postulation of the Social Learning Theory posits that people learn and are socialized within a social context, through which they model their lives after learnt behaviours and the ascription of roles and statuses to males and females. 
In Nigeria, especially in the rural areas as already discussed in this paper, women are treated as inferior to men. Many grew up to know females in Yorubaland as 'obirin lasan lasan' which means women are of little worth. This conception needs to change, if the society desires faster and sustainable development.

\section{Recommendations and Conclusion}

The government, at all levels, civil society organizations and religious bodies should embark on awareness creation among the rural populace, especially the women themselves, on the need to be empowered economically in order to engender an accelerated development of the rural areas. Education and training of rural women should be vigorously pursued by the government.

Learning about improved production technologies and methods, new products and markets, business and life skills, will go a long way in liberating the rural women from excruciating poverty. Rural women need adequate information to improve the quality of their life and their environment. Rural women should be made to go through various vocational and skills acquisition programmes that will help them acquire the necessary expertise and capacities needed to improve their economic status and independence. Proper identification of the skill and capacity needs of rural women will reduce uncertainty and enable them to identify various alternatives to livelihood.

Women should always be allowed to participate and engage in decision making on matters concerning them for increased agricultural output and productivity, reduced poverty and enhance food security. Policy making processes must involve women at conception, formulation and implementation to ensure inclusiveness and effectiveness. In order for women to reap the benefits of improved agricultural technologies, tools and equipment suitable for women in terms of their scale of operation and energy should be manufactured and made available at affordable costs. All policies and customs restricting the right of women to land ownership must be abolished. Women should be allowed to own land as they desire like their male counterparts. Women should have unrestrained or unhindered access to agricultural inputs such as fertilizers, among others. More female agriculture extension workers should be trained in order to be able to serve the woman better in the rural areas. Relevant NGOs should intensify advocacy on challenges of the rural women and provide technical support to the women towards women empowerment.

Mechanisms should be put in place that will ensure that rural women have access to funds to improve productivity. Also, government, banks and other financial institutions should be lobbied for gender friendly loan packages. A savings culture through the co-operatives and thrift societies should be encouraged and developed among the women in the rural areas, through which soft loans could be granted to these women. All legal and cultural impediments 
towards women empowerment should be abolished and appropriate legislative and other measures, including sanctions where appropriate, prohibiting all discriminations against women should be adopted by the Nigerian government at all levels.

Also, rural women must discard their 'dependency' mindset so that they can become conscious of their abilities to change things, their families and their communities, and as a result become creative, self-dependent individuals. It is pertinent to emphasize that gender equity presupposes equal rights, opportunities and treatment for women and men, girls and boys in all spheres of life and should be institutionalized. This means that both men and women would be free to develop their personal abilities and make choices without the limitations arising from stereotypes or prejudices.

Guaranteeing such freedom is a positive step towards creating the conditions for sustainable development in Nigeria. It is then that a new learning and socialization process shall emerge, through which socio-economic empowerment will be devoid of gender considerations. It is believed that if these recommendations are implemented by government and relevant agencies, rural poverty will be greatly reduced to the extent that rural women will be better equipped to contribute their quota to national development.

\section{References}

Abumere, S.I. 1991. Geography of Esan in Esan Student Magazine. A Magazine of Esan Student Association of University of Ibadan. Vol. 2.

Abdullahi, M.R. 2006. Women in Agriculture: The Role of African Women in Agriculture. National Agricultural Extension and Research Liaison Service, Ahmadu Bello University, Zaria, Nigeria.

Abdullahi A.A., Adekeye S.D. \& Shehu R.A. 2011. Towards Improving Gender Relations in Nigeria: Implications for Sustainable Development. Journal of Sustainable Development in Africa. 13(8): 239-253.

Adebayo, A.A. 2013a. Domestic Violence and Death: Women as Endangered Gender in Nigeria. American Journal of Sociological Research. 3(3): 5360.

Adebayo, A.A. 2013b. Domestic Violence Against Women: Nigeria Society in Discourse. Benin Journal of Gender Studies. 3(1\&2): 55-68.

Ajah, J. 2010. Evaluation of Women Farmers' Perception of the Impact of Women-in-Agriculture Programme on Yield, Income and Decision-making Power in Southeastern Nigeria. Journal of Agricultural Extension. 14(2): 24-34.

Ajani, O.I. 2008. Gender Dimensions of Agriculture, Poverty, Nutrition and Food Security in Nigeria. International Food Policy and Research Institute. Brief No. 5.

Alade, I.A. 2013. Gender Inequalities in Developing Nations. Benin Journal of Gender Studies. 3(1\&2): 94-112). 
Bandura, A. 1977. Social Learning Theory. New York: General Learning Press.

Central Bank of Nigeria. 1994. Statistical Bulletin. 5(2): 130.

Chiebowska, K. 1990. Literacy for Rural Women in the Third World. Paris: UNESCO.

Dada, O.M. 2011. Gender Issues in Agricultural and Rural Development. In Adedoyin, S.F. (ed.). Rural, Agricultural and Environmental Sociology in Nigeria. Nigerian Rural Sociological Association. Ibadan: Andkolad Publishers Nigeria Ltd.

Danziger, N. 2009. Rural Women and Migration. International Organization for Migration Publication, MSL0097. Available on www.iom.int/jahia/webdav/shared. Retrieved on May 3, 2013.

FAO. 1979. Review of the United Nations on FAO and World Conference Resolutions Concerning Agrarian Reform and Rural Development. (WCARR/INF. 1).

FAO. 2002. Report to "The New Partnership for Africa's Development": Land and Water Resources Issues and Agricultural Development. $22^{\text {nd }}$ Regional Conference for Africa, Cairo. 4-8 February 2002.

FAO. 2009. Reducing Children's Food Insecurity through Primary Education for Rural Mothers: The Case of Mozambique. Rome.

FAO. 2010. Investing in Skills for Socio-economic empowerment of rural women. Gender and Rural Employment Policy Brief. No. 2.

Gusim, T.T. 2012. Empowering Women Can Change Everything. Being a Paper presented at the International Women's Day Celebration 2012, Minna - Niger State.

Hacker, H. 1972. Women As a Minority Group. In N. Glazer-Malbin and H.Y. Waehrer (eds.). Woman in a Man-Made World. London: Hienemann.

Haralambos, M. \& Holborn, M. 2007. Sociology: Themes and Perspectives. $7^{\text {th }}$ Edition. London: HarperCollins Publishers Ltd.

IFAD. 2009. Ifad.org.operations/region/factsheets/ng. Retrieved on July 2, 2013.

IFAD. 1993. The State of World Rural Poverty: A Profile of Africa. International Fund for Agricultural Development, Rome.

IFAD. 2011. Women and Rural Empowerment. International Fund for Agricultural Development, Rome.

Ifemeje, S. and Ikpeze, O. 2012. Global Trend Towards Gender Equality: Nigeria's Experience In Focus. Kuwait Chapter of Arabian Journal of Business and Management Review. 2(3): 52-63.

IFPRI. 2009. Citizen Report Card. http://www.ifpri.org/publication/agricultural-extension-ethiopia-through-gender-and governance-lens. Retrieved on May 15, 2013.

ILO. 2008. Report IV: Promotion of Rural Employment for Poverty Reduction. Geneva. 
Itua, P.O. 2012. Legitimacy, Legitimation and Succesion in Nigeria: An Appraisal of Section 42 (2) of the Constitution of the Federal Republic of Nigeria 1999 as Amended on the Rights of Inheritance. Journal of Law and Conflict Resolution. 4(3): 31-44.

Jutting, J. and Morrisson, C. 2009. Women, Bad Jobs, Rural Areas: What Can "SIGI" tell us? Paper Presented at the workshop on "Gaps, Trends and Current Research in Gender Dimensions of Agricultural Employment: Differentiated Pathway out of Poverty." FAO-IFAD-ILO, Rome.

Kotze, D.A. 2003. Role of Women in the Household Economy, Food production and Food Security: Policy Guidelines. Outlook on Agriculture. 32: 111-121.

Mill, J.S. 2006. On Liberty and Subjection of Women. USA: Penguin Classics.

Modupe, F.M. 2008. Economic implication of poverty alleviation programmes on rural women in Ondo state: case study of Country Women Association of Nigeria. Journal of Social Sciences. 4(4): 352-357.

Momodu, M.O. 2002. Information needs and information seeking behaviour of rural dwellers in Nigeria: a case study of Ekpoma in Esan West Local government area of Edo State, Nigeria. Library Review. 51(8): 406-410.

Nnadozie, B. and Ibe, I. 1996. Women in Agriculture: Problems and Prospects, In: Agricultural Transformation in Nigeria. Nwosu, A.C.; Nwajuba, C.U. \& Mbanasor, J.A. (eds.). Owerri, Nigeria: Novelty Industrial Enterprises.

Ogunlela, Y.I. and Mukhtar, A.A. 2009. Gender Issues in Agriculture and Rural Development in Nigeria: The Role of Women. Humanity and Social Sciences Journal. 4(1): 19-30.

Okello, D. 2007. Empowering women through ICT: Enhancing access to information by rural women. http//www.govmonitor.com/node/1454. Accessed February 2nd, 2009.

Oladeji, M.O. 2009. Dimensions of Domestic Violence Against Women In Nigeria. In Kehinde, A. (ed.). Gender and Development. Essential Readings. Ibadan: Hope Publications Ltd.

Olujimi, B. 2009. Integrating Women In Nigeria Polity for Growth and Development: Perspectives from Obasanjo's Administration (1999-2007). In Kehinde, A. (ed.). Gender and Development. Essential Readings. Ibadan: Hope Publications Ltd.

Oluwasola, O. 1998. Women in Agriculture in Nigeria. In Sesay, A. and Odebiyi, A. (eds.). Nigerian Women in Society and Development, Ibadan: Dokun Publishing House.

Onwubiko, C.P.C. 2012. Empowerment of Nigerian Women Towards National Development. Journal of Resourcefulness and Distinction. 2(1): 68-78.

Osuji, F. 2004. Our Youth, Our Hope. Paper presented at the $47^{\text {th }}$ Session of the International Conference on Education, Geneva. 8-11 September.

Prakash, Daman. 2003. Rural Women, Food Security and Agricultural Cooperatives. New Delhi: Rural Development and Management Centre. 
Quisumbing, A. 1996. Male-Female Differences in Agricultural Productivity: Methodological Issues and Empirical Evidence. World Development. 24(10): 1579-1595.

Rahman, S.A. 2008. Women's Involvement in Agriculture in Northern and Southern Kaduna. Journal of Gender Studies. 17: 17-26.

Shittu, A.K. 2009. Education of Rural Women: Catalyst to Achieving Vision 2020 Objectives in Nigeria. In Kehinde, A. (ed.). Gender and Development. Essential Readings. Ibadan: Hope Publications Ltd.

UN Millenium Project. 2005. Investing in Development: A Practical Plan to Achieve Millennium Development Goals. New York.

Women and poverty. http://beijing20.unwomen.org/en/in-focus/poverty. Retrieved on June 15, 2013.

World Bank. 2006. World Development Report. New York: Oxford University Press. 